\title{
A COMÉDIA E A RUPTURA DOS SEMBLANTES: NOTAS SOBRE "AS NUVENS", EM LITURATERRA
}

Laura Lustosa Rubião

Psicanalista, mestre

em filosofia da

ciência pela

Unicamp,

doutoranda em

literatura

comparada pela

Universidade

Federal de Minas

Gerais.

RESUMO: O presente artigo retoma o trecho do texto Lituraterra, em que Lacan se refere à comédia As nuvens, de Aristófanes, com o propósito de ampliar suas possibilidades de leitura, por meio do retorno à peça do comediógrafo grego e a outras referências da obra lacaniana sobre a comédia. O texto deverá mostrar em que medida o recurso à comédia, compreendido a partir do instrumental teórico da Psicanálise, opera em favor de um movimento denominado por Lacan "a ruptura dos semblantes”, engendrando uma nova maneira de conectar o significante ao gozo.

Palavras-chave: Lacan, comédia, semblante, significante, gozo.

ABSTRACT: The comedy and the rupture of semblants: comments on "Clouds" in Lituraterre. This article reviews the part of Lacan's Lituraterre where the author mentions Aristophane's comedy Clouds. We want to enlarge its reading possibilities through the return to Aristophane's play and also, to other references of Lacanian work on comedy. We will show how the psychoanalysis' vision of comedy is connected to something called by Lacan as the rupture of semblants, creating a new way of linking the significant to the jouissance.

Keywords: Lacan, comedy, semblant, significant, jouissance.

$\mathrm{N}$ este artigo, faremos um comentário a respeito da passagem do texto Lituraterra, em que Lacan menciona As nuvens (peça do comediógrafo grego Aristófanes) com a finalidade de depreender o sentido da convocação do nome do poeta cômico, nesse contexto final da obra lacaniana.

Os escritos de maturidade de Lacan estão mais carregados daquela "nebulosidade" do sentido, com a qual já havia se habituado o leitor de seus escritos anteriores, reunidos na coletânea de 1966. 
Um comentário acerca de um texto lacaniano desse período terá, em função dessa característica, não o mérito de uma decifração - pois se torna vã toda tentativa de organizar o texto de maneira global, recuperando-lhe o sentido mas, tão somente, a vantagem de se levantar as possíveis ressonâncias que se fazem sentir internamente, a partir de um fragmento ou, ainda, de colocar esse mesmo fragmento em diálogo com outras passagens da obra do autor.

Estaremos, portanto, à procura de certos nexos (internos ou externos ao corpus teórico lacaniano), que possam contribuir para ampliar esse pequeno trecho do texto Lituraterra. Mais precisamente, nossa questão poderá ser formulada da seguinte maneira: o que justificaria a presença do nome de Aristófanes no referido artigo? Qual o sentido dessa evocação no que diz respeito ao interesse mais amplo da Psicanálise por peças de comédia?

Partiremos do pressuposto de que o termo nuvens, tal como empregado por Lacan em Lituraterra, está carregado de um valor significante, que não deixa de encontrar correlações com seu emprego na peça homônima de Aristófanes.

O comentário proferido por Lacan a respeito dessa mesma comédia (seminário As formações do inconsciente, de 1958), nos ajudará a localizar o germe da argumentação teórica presente no artigo de 1970, em especial no que diz respeito aos conceitos de saber e gozo e sua articulação a partir da comédia.

Finalmente, será preciso examinar mais de perto a noção de semblante, em torno da qual podem ser formuladas muitas das questões pertinentes a um estudo sobre a apreensão que faz a Psicanálise a respeito da comédia antiga.

\section{AS NUVENS DE ARISTÓFANES}

\section{Resumo da peça}

A peça As nuvens foi apresentada no festival das Grandes Dionísias no ano de 423 a.C., obtendo o terceiro lugar. A versão disponível aos estudiosos é posterior e nela são encontradas referências ao fracasso no concurso.

A trama, em linhas gerais, apresenta-nos o herói, Strepsíades, um velho fazendeiro às voltas com dívidas contraídas pelo filho perdulário, fanático por cavalos. Decidido a encontrar uma solução para seus problemas, procura Sócrates, que presidia o “pensatório”, espécie de escola propagadora dos conhecimentos sofísticos ou da arte de fazer a "pior causa parecer a melhor", por meio do ingresso em um "moinho de palavras” (v.260). Sócrates e seus discípulos não veneram os deuses olímpicos, mas sim as nuvens, representadas na peça por um coro de mulheres. Saber fazer com as palavras é o que demandava o velho campesino à escola socrática. Mas, não tendo demonstrado habilidade suficiente para tanto, envia, a contragosto, o filho Fidípides em seu lugar. Este é apresentado aos pensamentos justo e injusto, que travam um debate, do qual sai o último vencedor. Strepsíades consegue livrar-se de seus credores por meio dos 
ensinamentos obtidos pelo filho, mas há uma reviravolta ao final, pois este é capaz de provar, lançando mão dos mesmos ensinamentos, que é justo espancar o pai e o faz. Revoltado, Strepsíades decide atear fogo no pensatório.

Antes de abordarmos os aspectos semânticos caros ao termo nuvens, que dá título à peça, será preciso examinar mais de perto o sentido da inserção dos sofistas na sociedade grega do século V a.C., o que facilitará o entendimento da trama construída por Aristófanes.

\section{Os sofistas}

A sofística, movimento que abriu as perspectivas de uma nova educação para o povo grego, surgiu no contexto da criação da polis e da constituição da nova sociedade civil, no espírito do regime democrático. Sua finalidade, esclarecenos Jaeger, era a “superação dos privilégios da antiga educação para a qual a Arete só era acessível aos que tinham sangue divino” (JAEGER, 1995, p.337). O acesso a lugares de destaque político não mais dependia de uma hierarquia natural, mas de um exercício de retórica, que implicava, sobretudo, o bom manejo das palavras.

Os sofistas passaram a exercer, na ocasião, o papel de mestres da sabedoria, função antes reservada aos poetas. Eram, em geral, estrangeiros e cobravam honorários por seus préstimos. Seu ensinamento voltava-se para os chefes e não para o povo: "no fundo não era senão uma nova forma da educação dos nobres" (JAEGER, 1995, p.339).

Esse movimento, de extraordinária importância para a cultura grega, baseavase no princípio geral, segundo o qual a natureza humana (physis) seria passível de ser moldada, aprimorada e cultivada pela educação, assim como o corpo pode ser treinado por meio da ginástica.

Se, por um lado, os ensinamentos sofísticos floresceram no seio da constituição do estado democrático e praticamente surgiram como uma exigência desse novo ambiente político, por outro, tornaram-se amplamente disponíveis, passando a servir também a inimigos do Estado, como poderosa arma na luta pelo poder. O grande debate que daí advém diz respeito, justamente, às implicações decorrentes do uso que se podia fazer dessa arte retórica, uma vez que a natureza humana não obedecia ao princípio da igualdade, previsto no regime democrático (JAEGER, 1995).

Esse movimento de torção ou de virada, em que uma determinada tendência - seja ela representada por um discurso, uma instituição ou uma política toma o sentido contrário do que estava previsto em seus princípios, é uma constante no teatro de Aristófanes, muito atrelado à realidade de seu tempo. No caso específico de As nuvens, o que fica patente na crítica aos sofistas são os efeitos inesperados decorrentes do reino da palavra, o qual se pretende controlar: tão 
plástico e escorregadio, quanto traidor e incontrolável. Tudo isso, à revelia das boas intenções dadas por princípio.

\section{A ambigüidade das nuvens}

Não é difícil notar, ao longo da leitura da peça de Aristófanes, a existência de um jogo com o termo nuvens que dá título à peça. As circunstâncias dramáticas apresentam-no pleno de ambigüidades. Suas características oscilam entre o peso e a leveza, a fúria e a sutileza, a materialidade física e a imaterialidade etérea (como metáfora do pensamento).

Interessa-nos em particular esta dicotomia corpo/pensamento (matéria e idéia), presente nas discussões filosóficas a respeito da operacionalidade ou não da educação (por meio da palavra) sobre a natureza humana, por ocasião do movimento sofístico. Esta é uma oposição passível de ser traduzida no par 'significante/gozo', essencial à leitura do texto Lituraterra.

Logo no início da peça, um discípulo de Sócrates relata as proezas de seu mestre ao recém chegado Strepsíades. Observa-lhe que Sócrates, havia se dedicado a um estudo sobre os intestinos dos mosquitos, conseguindo constatar sua estreiteza, compatível com a pressão da passagem do ar e com a violência do sopro. O interlocutor emite elogios ao autor dessa intesti...gação:

Strepsíades: E o que disse Sócrates sobre os mosquitos?

Discípulo: Ele afirmava que os mosquitos tinham o intestino estreito; ora, o canal sendo assim delgado, o ar passa com força até o rabo; depois, saindo pelo reto apertado, faz o ânus ressoar pela violência do sopro.

Strepsíades: Então o ânus dos mosquitos é uma trombeta! Três vezes feliz é o autor dessa intesti...gação. ${ }^{1}$ (v.160-167)

O ar, matéria de que são compostas as nuvens, refere-se também aos gases do corpo, o que, para além do efeito risível da piada, toca a dimensão do resto, do excremento, da imundície ${ }^{2}$ que não deixará de ter importância para a nossa discussão.

As nuvens representam a discrição e a leveza dos vapores, pois simbolizam (como deusas do pensatório) a sutileza do espírito na forma do saber engenhoso

\footnotetext{
${ }^{1}$ Nesse passo, temos uma palavra forjada pelo poeta $(\Delta \mathrm{t} \varepsilon v \tau \varepsilon \varpi \rho \varepsilon v \mu \alpha)$ que alude tanto a

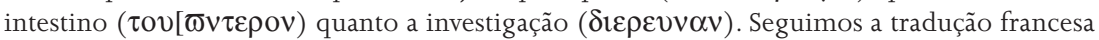
que propõe intesti...gation; vertendo para o português temos intestigação.

${ }^{2}$ Segundo Lacan, o que advém da ruptura de um semblante é o gozo com seu componente de imundo ou (i)mundo, o elemento propriamente pulsional que age em favor da vida. Cf. Lacan, Lituraterra, op. cit., p.22.
} 
e mutante: "são as Nuvens celestes, grandes deusas dos ociosos: elas nos dispensam saber, dialética, entendimento, linguagem prestigiosa e verbosa, arte de comover e enganar" (v.316-19). Mas, as nuvens expressam, ao mesmo tempo, toda a violência dos sopros, sob a forma de raios e trovoadas até se romperem em temíveis tempestades.

Assim se expressa a crítica aristofânica à pretensão da arte retórica que se nutre, necessariamente, do aspecto plástico, móvel e fugidio da linguagem, sempre a proporcionar a proliferação dos sentidos, os giros da eloqüência, a sedução da metáfora. As nuvens não têm forma capturável, transformam-se no que desejam, explica Sócrates ao fazendeiro:

Sócrates: Já te aconteceu de olhar para cima e ver uma nuvem parecida com um centauro ou com um leopardo ou com um lobo ou com um touro?

Strepsíades: Sim, o que isso significa?

Sócrates: Elas se transformam no que desejam. (v.349)

Esse eterno transformar-se é, entretanto, passível de ruptura, estrondo, imprevisibilidade. As nuvens são feitas da leveza do éter, mas transportam os raios e os trovões, tal como as evoca Sócrates:

Sócrates: Oh mestre soberano, Ar infinito que sustenta a terra suspensa no espaço, Éter brilhante e vós, veneráveis deusas, Nuvens que transportais o trovão e o raio, levantai, aparecei do alto dos ares, ao pensador. (v.261-266)

Se a palavra serve para tudo, poder-se-ia conjeturar, não tem em si um fim elevado, pode ser agregada aos humores fétidos do corpo. Sem estar regida por nenhuma ética superior, a linguagem não aparta os domínios do corpo e do pensamento, do real e do simbólico. A palavra pode vir a ser, ela própria, esse ponto de confluência, esse espaço litoral em que elementos heterogêneos vêm se fundir. Eis-nos já em pleno domínio da letra, conceito-chave para a construção do texto Lituraterra. O mesmo elemento ar componente da textura das nuvens congrega o peso e a leveza, o elevado (pensamento) e o baixo (corpo como resto e dejeto).

É nas incrustações da própria palavra que essa dimensão da letra se faz ouvir no registro da comédia, no momento em que o fazendeiro aprendiz é levado a se convencer da articulação entre os estrondos celestes e os turbilhões corporais do baixo ventre: 
Strepsíades: É por isso então que as palavras peidar e trovejar terminam em “...ar”? $(\text { v.394 })^{3}$

\section{AS NUVENS EM LITURATERRA}

O texto Lituraterra tem por inspiração um sobrevôo. Uma visão que se esboça por entre frestas de nuvens, do alto de uma planície siberiana. Os traços gravados na terra pelo escoamento das águas (LACAN, 1970/2003), vistos do alto, formavam sulcos, reentrâncias na terra, entalhes, marcações. Essas imagens serviram de estofo para a elaboração do conceito de letra a partir do de escritura, dos efeitos de impressão, apagamento e rasura, que exprimem todo o caráter material da escrita e sua dimensão corporal, tão bem expressa no estilo ideográfico. O conceito de letra, construído tardiamente no ensino de Lacan, vem demarcar uma fronteira em relação a toda uma concepção psicanalítica anterior, que enfatizava a vertente interpretativa do significante, produtor de enigmas na encruzilhada entre sintoma e desejo inconsciente. A letra permite a inscrição de um gozo insensato que não mais convida ao trabalho de decifração.

A reescrita do termo literatura como lituraterra, à maneira de um chiste, encerra um exercício crítico, talvez comparável ao que vimos com relação aos efeitos da comédia aristofânica. Em ambos, a ordem do saber estabelecido será questionada: as belas letras de um lado, o saber oficial das elites políticas, de outro.

Talvez, por isso, tenha sido a presente comédia inserida no contexto do artigo de Lacan, do ponto de vista do efeito de ruptura:

"O que se revela por minha visão do escoamento, no que nele a rasura predomina, é que, ao se produzir por entre-as-nuvens, ela se conjuga com sua fonte, pois que é justamente nas nuvens que Aristófanes me conclama a descobrir o que acontece com o significante: ou seja, o semblante por excelência, se é de sua ruptura que chove, efeito em que isso se precipita, o que era matéria em suspensão." (LACAN, 1970/ 2003, p.22)

Caberia aqui recolocar nossa questão: por que justamente as nuvens de Aristófanes seriam convocadas a demonstrar a conexão entre o significante e o semblante, cuja ruptura deixa entrever os efeitos de gozo?

Antes de nos dedicarmos a buscar desdobramentos para essa passagem, seria

\footnotetext{
${ }^{3}$ A sutileza do pensamento socrático, nessa peça, é sempre tratada com boa dose de ironia como mostra o trecho sobre a pesquisa com o intestino dos mosquitos. Essa ironia dirige-se às novas tendências filosóficas da Grécia do século V, que preconizavam o homem como estando no centro das coisas, inclusive, no centro das descobertas científicas. A ironia estaria em atrelar a imponência do saber emergente à insignificância de pesquisas como essas.
} 
oportuno recuar um pouco na obra lacaniana, com a intenção de retomar uma abordagem anterior, feita pelo autor sobre a mesma comédia.

\section{0 isso calça as botas da linguagem}

No seminário intitulado As formações do inconsciente, é reservado um espaço para se pensar a comédia e sua relação com o inconsciente, a linguagem, o isso, a satisfação.

Ao identificar a origem da comédia como estreitamente ligada à "relação do isso com a linguagem" (LACAN, 1957-58/ 1999, p.139-40), Lacan menciona o banquete cômico, no qual se celebra a fruição dos prazeres do corpo, a grande festa do vinho, da embriaguez, dos excessos em geral. Essa comunhão entre isso e linguagem alude à presença do gozo, elemento que se destaca do campo do simbólico (nesse momento do ensino do autor a separação é mais evidente), mas que, em algum momento, por efeito de uma reviravolta, apodera-se da rede significante em proveito próprio: “É sempre o momento em que o isso faz uma reviravolta em proveito próprio, calça as botas da linguagem para seu uso, o mais elementar" (LACAN, 1957-58/1999, p.140).

Nesse enquadramento teórico, evoca-se a peça As nuvens e a transformação da "bela dialética socrática” em objeto da satisfação particular de um velho fazendeiro (LACAN, 1957-58/1999, p.140). A linguagem é tomada em um uso particularizado, a serviço da satisfação de um sujeito: nada mais contrário ao ideal de igualdade proposto pela democracia, nada mais aberrante quando se associa o saber à mestria política e nada, contudo, mais verdadeiro, quando se levam às últimas conseqüências os poderes da palavra, tomada em sua literalidade, em sua vizinhança com o resto e o dejeto.

O tiro pode sair pela culatra, um filho pode provar ao pai, valendo-se de argumentação lógica, que é justo espancá-lo, desde que use a linguagem em favor de seu gozo. O pai, aquele que sonhava ter o domínio completo das palavras, vê-se barrado, limitado pelo gozo do Outro:

Fidípides: Como é doce viver entre coisas novas e engenhosas e poder desprezar as leis estabelecidas! Assim, quando apenas a equitação me retinha a atenção, eu não era capaz de dizer três palavras sem cometer um erro, mas agora, desde que meu mestre pôs fim a tudo isso e que me familiarizei com os pensamentos sutis, raciocínios e meditações, creio poder provar que é justo castigar meu pai. (v.1400-1406)

É aguda a ironia do poeta cômico, que faz cumprir, em toda sua literalidade, a promessa ambiciosa do projeto sofístico: se com a palavra faz-se o que se quer, defendem-se tanto raciocínios justos quanto injustos, então, aquele que se pretende de posse de sua mestria não estará imune aos efeitos devastadores, que daí 
possam advir. Assistimos à rasteira do protagonista que, da posição de dominador passa à de dominado, lançando-se, sem que possamos deixar de rir, num terreno que lhe é estrangeiro.

É o mesmo modelo seguido por Lacan, ao mencionar o teatro clássico de Molière, na seqüência de seu comentário, no seminário V. Trata-se da peça Escola de mulheres, em que o herói Arnolf, esforça-se por fazer de sua mulher uma ignorante, na certeza de que assim estaria seguro a respeito de sua obsessão fantasmática de não ser traído. A educação que recebe Agnes volta-se contra o marido, pois ela, mantendo sua ingenuidade, usa tão bem as palavras, conforme seu desejo, que é capaz de escapar sempre, fugindo ao controle de seu esposo e pretenso proprietário (LACAN, 1957-58). Em cenários distintos, assistimos ao mesmo drama (Será trágico? Será cômico?), que revela a impossibilidade de se obter o domínio do campo da linguagem, por meio da educação ou do exercício sofístico.

Mesmo levando-se em conta os diferentes patamares teóricos em que se dão essas duas abordagens (a de 1958 e a de 1970), é importante notar uma conversão das perspectivas, que pressupõe na estratégia da comédia uma espécie de assalto da linguagem pelo gozo, uma forma de enlace entre o simbólico e seu deslizamento metonímico e o real, que é um ponto de parada, de estancamento da cadeia.

\section{A ruptura de um semblante}

O significante é, por excelência, o semblante. A metáfora das nuvens alude, até certo ponto, à esfera do significante, por sua textura vaporosa, volátil, instável, como vimos a propósito de sua inserção no contexto da peça de Aristófanes, em que elas representam a particularidade mutante das palavras que servem para tudo. Alude também, claramente, ao domínio dos semblantes, uma vez que tocam o domínio do parecer, promovendo o intercâmbio das imagens. As nuvens são dotadas, simultaneamente, de um componente de violência, que marca a interrupção desse processo de transmutação: podem gerar os raios, as trovoadas estrondosas, as tempestades.

O conceito de semblante surge tardiamente na obra de Lacan, após sua formulação dos quatro discursos. Miller esclarece-nos as sutilezas de sua composição conceitual, ao indicar que o semblante não pertence unicamente ao campo do engodo e das formações enganosas. Ao interceptar os registros do simbólico e do real, os semblantes nos revelam algo da verdade de um sujeito, o seu substrato de ser. Lacan joga, inclusive, com o termo francês par(être), para apontar a conjunção do ser ao parecer (MILLER, 1988, p.3).

O pai, o falo, a mulher e a própria linguagem são exemplos recolhidos por Lacan para discernir os diversos modos de se operar com o semblante. Em linhas gerais, trata-se sempre de encontrar recursos para lidar com o lado insuportável 
da desproporção entre os sexos, de forma a se produzir um parecer. Mas, o semblante vem envelopar sempre o vazio, fazer crer que há o que, de fato, não há (MILLER, 1988, p.7). ${ }^{4}$

Miller aponta-nos, ainda, o fato de não parecer tão óbvia a conexão da cadeia de significantes à função do semblante, uma vez que sua raiz conceitual, o estruturalismo lingüístico, concedera-lhe o formato de um sistema de oposições que implica uma necessidade lógica, um funcionamento mecânico, mantendo-se estável como uma estrutura que se repete de forma autônoma, a despeito da vontade subjetiva (MILLER, 1988). Digamos que o conceito de semblante seja um conceito fronteiriço, de dupla face, uma que se volta para o real e outra para o simbólico. A parte final do ensino de Lacan tende justamente a manter os registros (Real, Simbólico, Imaginário) mais próximos, o que surte efeitos em sua concepção da linguagem. A nuvem significante é uma construção distinta da de cadeia significante, pois aí estão previstos os efeitos do gozo (MILLER, 1988).

No texto Lituraterra é propriamente o gozo que vem jorrar, quando o semblante se rompe, e é isto que trazem ao primeiro plano as nuvens de Aristófanes, segundo a apreciação de Lacan. Os sulcos cavados na terra constituem a imagem exemplar das ranhuras da escritura, passíveis de sobrepor as marcas diferenciais e o fluxo material do gozo, afinal composto da mesma matéria que formara o conglomerado de nuvem. Em relação a esse aspecto, é esclarecedor o comentário de Mandil sobre o texto Lituraterra, ao observar que há tanto continuidade quanto descontinuidade entre os elementos em questão:

\footnotetext{
"Nuvens e riachos não se confundem, ainda que uma conjugação entre eles possa ser pensada, uma vez que a nuvem pode ser concebida como um dos lugares de onde os riachos derivam. Não se confundem porque há entre eles descontinuidade, representada pela precipitação." (MANDIL, 2003, p.52)
}

Seria interessante observar que o texto de Aristófanes explora de forma abundante o trabalho material com as palavras. É notável a presença de jogos de linguagem, chistes, neologismos que, com muita freqüência, trazem ao primeiro plano a dimensão corporal das palavras, sua capacidade de fisgar o afeto e de injetá-lo no plano simbólico. Se essa expressão dramática tem por pressuposto a contestação da estabilidade discursiva, mostrando a face intrusiva do gozo que

\footnotetext{
${ }^{4}$ Para consultar as obras de Aristófanes, optamos por adotar a edição francesa da Belles Lettres. Nesse passo, contudo, a tradução para o português é especialmente bem sucedida, pois a terminação ar das formas verbais provoca ressonância com o substantivo ar em questão na peça e enfatizado por nossa argumentação. Na tradução francesa, temos apenas a transliteração das

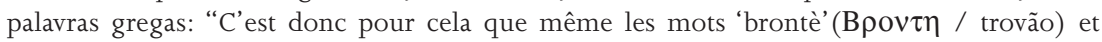
'pordè' ( $\pi$ o $\delta \eta \omega /$ peido) se ressemblent." (v.395).
} 
resiste a uma contabilização prévia, ela o faz por meio de um trabalho que opera ao nível da própria materialidade do significante. O seu mérito será, do ponto de vista da psicanálise, o de trazer à cena o semblante em estado de ruptura como pudemos observar, a partir da peça comentada.

\section{0 império dos semblantes}

O texto Lituraterra avança em considerações a respeito da cultura japonesa e de suas conexões com a escrita (escritura). Ao título do livro de Roland Barthes, O império dos signos, Lacan apõe a expressão “império dos semblantes”, no intuito de extrair, de acordo com seu ponto de vista, as conseqüências maiores deste belo livro.

Nele, encontramos um estudo sobre diversos eixos da cultura japonesa, tais como, a culinária, o urbanismo, a arte do embrulho ou embalagem (paquet), o teatro de marionetes, a escrita. A partir dessa variedade, procura-se discernir o que, nas palavras do autor, pode ser resumido como o "modo ideográfico de existir” (BARTHES, 1970, p.106) proeminente no Japão, onde os modos de expressão do cotidiano dispensam as inflexões teatralizadas (histericizadas), de que depende o narcisismo do homem ocidental (BARTHES, 1970, p.106).

Assim é que, de um modo geral, o “modo de existir japonês”, tão distante do nosso, põe em evidência uma espécie de véu decaído, num traçado plano, esvaziado das tergiversações comuns ao espírito ocidental, que exige os desvios da metáfora, no labirinto do sentido que se prolifera.

Dentre todas as esferas investigadas por Barthes, merece destaque especial a que trata da arte japonesa da embalagem, do empacotamento (paquet). No Japão é muito valorizada a prática de se embalar objetos e o que merece ser sublinhado, segundo Barthes, é o contraste entre a forma e o conteúdo: de um lado, a suntuosidade e riqueza dos embrulhos, de outro, a insignificância e derrisão do objeto embalado. Assim, podem ser encontrados um pequeno confeito ou uma lembrancinha vulgar, embalados de forma rica e sofisticada como se fossem jóias (BARTHES, 1970). Esse exemplo pode estender-se a outros aspectos da cultura em questão, como certas composições literárias (haikai) e a própria escrita ideográfica, no que aí predominam, nas palavras de Barthes, uma isenção e uma efração do sentido.

Nesse ponto concentra-se o interesse de Lacan, ao reportar a noção de signo à de semblante, pois no caso da segunda, ainda que prevaleça o gesto de ocultar, o que se oculta, de fato, é nada. Lembremos que um dos efeitos da comédia seria, por assim dizer, aproximar a forma (os discursos diversos: filosófico-Nuvens, literário-Rãs, jurídico-Vespas) do vazio que ela contém, trazendo-nos os semblantes em estado de ruptura, imagem tão bem expressa pelo significante nuvens.

Tomemos, de forma breve, o exemplo da peça As vespas, em que novamente figura a tensão entre pai e filho no contexto da relação com a lei jurídica. O pai, 
um velho que atende pelo sugestivo nome de Filocleão (amigo de Cleão, político corrupto contemporâneo de Aristófanes) lida de forma compulsiva com o ato de julgar e condenar os acusados na tribuna. Ao fazê-lo, acredita assumir a estatura de Zeus, todo poderoso. A trama se desenrola em torno das tentativas do filho Bdelycleão (contra Cleão) de mostrar ao pai sua condição velada de escravo aquele que serve, sem saber, ao interesse de terceiros, pois os juízes eram francamente explorados pela ação corrupta de políticos de peso, que lucravam grandes quantias com os processos. Nessa peça, a grande instituição dos magistrados perde sua consistência, seu ponto de apoio, pois a lei é tomada, aqui e ali, de forma clandestina, a serviço da satisfação particular dos sujeitos envolvidos. Em poucas palavras, talvez fosse possível dizer que o que perde, em última instância sua consistência, são as formas soberanas do poder absoluto, sorvidas pela ilusão do semblante que o artifício cômico vem dissolver.

A partir disso, julgamos poder correlacionar o próprio modo de operação da comédia com a estrutura do Witz freudiano, que combina os efeitos simultâneos de surpresa e revelação. Suspensos os encadeamentos fixos do código lingüístico, os ditos prefixados pela cultura, torna-se possível o proferimento de um novo dizer, fiel ao gozo particular de cada sujeito.

É digna de nota a composição da tríade dos deuses, a que devem respeito, na peça As nuvens, os seguidores de Sócrates: “o Caos, as Nuvens, a Língua” (v.425). A língua em conjunção com o caos remete-nos a esse estado e perturbação da linguagem, nomeado lalangue por Lacan. Esse estágio, anterior ao arranjo gramatical da língua, pode ser associado àquele detectado por Freud na origem da genealogia do Witz: o puro jogo verbal, que visa a um ganho de prazer (lustgewin) e encontra, na ratificação do riso do Outro, um modo de ancoragem no laço social (FREUD, 1905, p.148).

Vale lembrar ainda que, na peça de Aristófanes, o coro de nuvens é composto por mulheres, fato que causa a surpresa do herói, pois as nuvens não se parecem com mulheres. Mas, sua principal característica é terem a forma mutante e tornarem-se parecidas com o que quer que seja. A linguagem, suporte do saber representado pelas nuvens, colocada ao lado do feminino e de sua instabilidade fere, de certa maneira, o modo de concebê-la como uma estrutura, um sistema rígido, universal. ${ }^{5}$ Talvez essa conexão só seja possível no registro de alíngua (lalangue),

\footnotetext{
${ }^{5} \mathrm{O}$ conceito de semblante torna-se precioso para traçar a leitura lacaniana sobre a Comédia, no tocante à sua relação com o falo. A referência inicial (Seminário 2) pautava-se no conceito de falo imaginário: o universo cômico como mero espetáculo risível do falo. No seminário 5 , vimos que a ênfase da análise lacaniana recai, principalmente, sobre os efeitos do gozo, e no seminário 7 (A ética da psicanálise, p.340) encontramos, com relação à comédia, a referência ao falo como índice de escapada do gozo. Já em Lituraterra, com o conceito de semblante, podemos pensar o falo como esse envelope precário, artificial, sempre sujeito à derrisão da queda. Com
} 
em que se desloca, até certo ponto, o eixo em torno do qual está sedimentado o princípio organizador da linguagem, que, como todo semblante, está sujeito a rupturas. ${ }^{6}$

Os recursos propiciados pela estrutura da comédia - aqui comparada a de um Witz - atestam essa capacidade de tanger a fragilidade constitutiva dos eternos semblantes: A Ciência, a Filosofia, o Discurso Literário, a Política, o Amor e tantos outros. Essa intimidade com o semblante, permite ao sujeito (em análise) - ou, se quisermos, ao herói cômico, sempre às voltas com os grandes vultos da impostura - certa mobilidade frente ao Outro, cuja consistência lhe foi permitido esvaziar. Esse sujeito, assim comparado a certos personagens saídos do teatro cômico, terá sido afetado por uma dose de ceticismo, conquanto conceda com o desamparo que está na raiz de sua constituição subjetiva, ou seja, estará habilitado a manter em suspensão todo critério fixo de verdade. Todavia, longe de se comportar como o cético, que a tudo acusa como obra do semblante, mantendose em algum lugar à parte, ele se sabe, enquanto ser falante, irremediavelmente preso à estrutura da linguagem à qual pertence e da qual está excluído, pois terá renunciado ao posto de mestre das palavras. De modo astuto, ele já pode reconhecer os furos dessa estrutura, com os quais tem que lidar.

O fato de não haver critério fixo de verdade, não nos poupa dos efeitos súbitos e surpreendentes promovidos pelo teatro cômico em sua estrutura de Witz, ou seja, não nos autoriza pleitear o posto de mestria em relação às palavras. Sempre haveremos de nos deparar com a derrapagem do sentido e, conseqüentemente, com os impactos do real. Tais efeitos, dizem respeito à formulação de um novo modo de dizer, um modo de bem dizer o sentido inaudito em que o gozo é levado em conta (jouisense). Esses novos dizeres se inscrevem sob a rubrica de um discurso que, por conhecer a ordem do semblante, pode se furtar a ela, mantê-la a certa distância ou ainda, jogar com ela.

Manter em suspenso os critérios fixos de verdade, muitas vezes requeridos pelos discursos ditos totalizadores, não significa, portanto banir de nosso horizonte toda a perspectiva da verdade, se concordamos, com Lacan, que a verdade pode apenas ser semi-dita, ou seja, que é justamente no ato de se mostrar eclipsada que podemos reconhecê-la enquanto tal. A verdade para a psicanálise reside,

muita freqüência localizamos nas tramas aristofânicas esse movimento de destituição fálica, pois, o que está em questão é a fragilidade das instituições sociais (política, filosofia, literatura) ditadas, na época, pela ordem do poder masculino.

${ }^{6}$ Conferir as considerações feitas por Miller a esse respeito, indicadas ao longo de nossa discussão. Tudo indica que esse tipo de conexão (entre a linguagem e o feminino, entre a linguagem e o semblante) apenas possa ser feita, levando-se em consideração as teses tardias de Lacan, posto que, um longo percurso teórico terá sido necessário até que o próprio nome do pai tenha sido encarado como um artifício. 
exatamente, na expressão desse dizer lacunar e entrecortado, afetado pelo real, que acena, enfim, para a possibilidade de inclusão do gozo. É a verdade causada pela oportunidade do Witz, que detectamos nos mecanismos de composição de algumas comédias, sempre a nos propiciarem um riso acusador, quem sabe, da ruptura dos semblantes.

Recebido em 22/2/2006. Aprovado em 8/5/2006.

\section{REFERÊNCIASS}

ARISTOPHANE (1964) Les guêpes. Texte établie par Victor Coulon. Paris: Les Belles Lettres.

. (2002) Les nuées. Texte établie par Victor Coulon. Paris: Les Belles Lettres.

ARISTÓFANES (1995) As nuvens. Tradução de Mário da Gama Cury. Rio de Janeiro: Jorge Zahar.

BARTHES, R. (1970) L'empire des signes. Paris: Flammarion.

FREUD, S. (1976) Edição standard brasileira da obras psicológicas completas. Rio de Janeiro: Imago.

(1905) “Os chistes e sua relação com o inconsciente”, v.VIII, 148 p.

JAEGER, W. (1936/1994) Paidéia. São Paulo: Martins Fontes.

LACAN, J. (1954-1955/1985) O seminário livro 2, O eu na teoria de Freud e na técnica da psicanálise. Rio de Janeiro: Jorge Zahar.

. (1957-1958/1999) O seminário livro 5, As formações do inconsciente. Rio de Janeiro: Jorge Zahar.

. (1959-1960/1991) O seminário livro 7, A ética da psicanálise. Rio de Janeiro: Jorge Zahar.

. (1971/2003) “Lituraterra”, in Outros escritos. Rio de Janeiro: Jorge Zahar.

MANDIL, R. (2003) Os efeitos da letra: Lacan leitor de Joyce. Rio de Janeiro: Contra Capa.

MILLER, J. (1991-92) A natureza dos semblantes. Seminário inédito.

Laura Lustosa Rubião

lrubiao@terra.com.br 